\title{
The Chemical Channel of Earthquake Reactions and Decrease in the Magnitude of Earthquakes
}

\author{
Michael G. Noppe \\ Department of Applied and Theoretical Physics, NSTU (Retired), Kiryat Yam, Israel \\ Email: noppe.mg@gmail.com
}

How to cite this paper: Noppe, M.G. (2020) The Chemical Channel of Earthquake Reactions and Decrease in the Magnitude of Earthquakes. International Journal of Geosciences, 11, 84-99. https://doi.org/10.4236/ijg.2020.113006

Received: February 5, 2020

Accepted: March 13, 2020

Published: March 16, 2020

Copyright $\odot 2020$ by author(s) and Scientific Research Publishing Inc. This work is licensed under the Creative Commons Attribution International License (CC BY 4.0).

http://creativecommons.org/licenses/by/4.0/

(c) (i) Open Access

\begin{abstract}
The first necessary condition for the onset of an earthquake is the penetration of explosive gas into an explosive zone as a result of physical or chemical reaction. The second necessary condition is to ensure the subsequent propagation of the flame after ignition. The latter condition has made it possible to explain the impact of a cyclone on the emergence of 42 strongest earthquakes in the 21 st century. If violation of this condition can be achieved with the help of vibrators or explosions, this will result in a decrease in the magnitude of an earthquake or even a complete prevention of earthquakes. Thus, the second condition is essentially a "pressure lock" that opens (with a decrease in the pressure caused by a cyclone), which leads to an earthquake or closes (with an increase in the pressure caused by an anticyclone or human interference using vibrators or explosions), which leads to earthquake prevention. Kinetic equations of the 2nd type were used to describe chemical reactions and obtain formulas for the precursor time, which made it possible to describe earthquakes of the chemical channel. The set of experimental time values of the earthquake precursor described by the physical model includes about $20 \%$ of all earthquakes; $80 \%$ of earthquakes can be attributed to the chemical channel for earthquakes that occurred in Dushanbe in 1983. All earthquakes in Tiberias in June 2018 passed through the chemical channel, which can be concluded from the small magnitude of these earthquakes. Several proposals have been made, including: 1) creating a new sensor for the geochemical method, which allows determining the epicenter of a future earthquake; 2) creating a network of stations with a new sensor for determining the epicenter and an atmospheric pressure meter installed at each station (this will determine if the "pressure lock" is closed by an anticyclone, which can lead to a decrease in the magnitude of an earthquake or even prevent an earthquake); 3 ) installing vibrators in epicenters (or making daily explosions with explosives delivered by trucks, drones, airplanes or helicopters, which should lower the magnitudes of future dangerous earthquakes); 4)
\end{abstract}


alerting the public to the expected future earthquake; 5) developing specialized vibrators for reducing the magnitude of an impending catastrophic earthquake. Thus, this article is a breakthrough, describing a new mechanism in earthquakes for understanding and theory of earthquakes, which are used for the vast majority of earthquakes, including for program to reduce the magnitude of dangerous earthquakes.

\section{Keywords}

Earthquakes Prediction, Physical Model, Earthquake Condition, Precursor Time Formula, Kinetic Equations for Chemical Reactions, Necessary Conditions for Earthquake

\section{Introduction}

"The father of modern geology"-Sir Charles Lyell argued [1]: “The primary causes of the volcano and the earthquake are to a great extent the same, and connected with the development of heat and chemical action at various depths in the interior of the globe." After the strongest earthquake of 1906 in San Francisco, the mechanistic hypothesis by H.F. Reid [2] caught on: the plates on the opposite sides of the fault are subjected to pressure and accumulate stress reaching a certain critical value until a "breakdown" occurs, at which the accumulated elastic recoil energy is released, partly in the form of heat, and partly in the form of elastic waves, which amount to an earthquake. The theory of stress accumulation in the Earth's crust does not provide a convincing explanation for many phenomena and, in particular, deep-focus earthquakes, because at a depth of more than $20 \mathrm{~km}$, the rocks become plastic and cannot accumulate any stresses, due to the temperature increase with depth. By the 21st century, a lot of facts have been accumulated that confirm the following opinion: the reasons for the earthquake are explosions, the energy of which is the degassing energy of primary hydrogen and helium, the main elements captured during the Earth's formation and "packed" in its core and mantle in the form of explosive gases, solid solutions and chemical compounds (Gilat and Vol [3] [4]).

What conditions are necessary for an earthquake and what is the physical and mathematical model of the process? Explosive gas passes between continental and oceanic plates and rushes to the surface of the Earth. Consider the gas flow densities Hg presented in Figure 1 (from patent Staheev Yu.I., et al. [5]). The delta-like flow of $\mathrm{Hg}$ gas and explosive gases in the area adjacent to the fault fills the traps with explosive gas throughout the region, turning them into sources of future earthquakes.

The flow of other explosive gases, mainly methane, as methane makes up 98\% of natural gas, will be proportional to the flow of $\mathrm{Hg}$. A mixture of gas and air is explosive only if the concentration of flammable gas in it is between the lower LEL and the upper explosion limits UEL. 


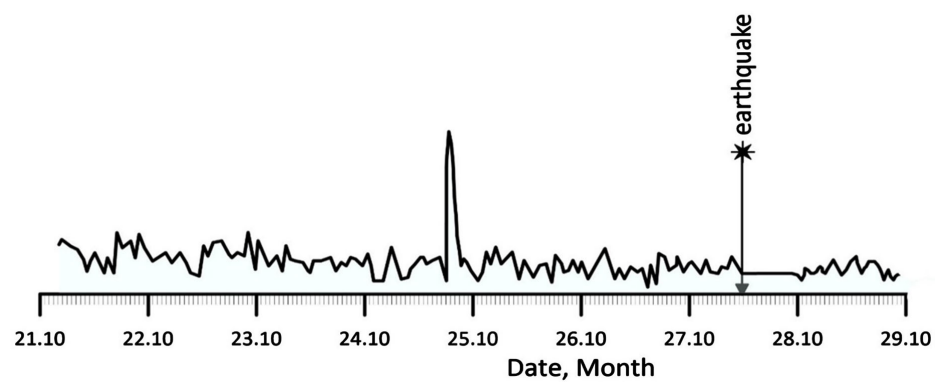

Figure 1. Experimental time dependence of the gas flow density $\mathrm{Hg}$ (from patent Staheev Yu.I., et al. [5]).

The high concentration of explosive gas in the focus will begin to decrease by some mechanism until its concentration reaches the explosive zone (LEL, UEL), in which an explosion can occur.

Thus, the first necessary condition for the onset of an earthquake is the need for an explosive gas to enter an explosive zone in which an explosion can occur, which will lead to an earthquake (M.G. Noppe [6] [7]). The physical diffusion mechanism was described in the cited articles, a formula was derived for the dependence of the precursor time on the magnitude of the earthquake, which gave an explanation only for a certain number of earthquakes (see figure 3(a) from the article by Yu. I. Staheev [8]). Obviously, other mechanisms are needed to explain the measurements of a large number of other earthquakes.

This article discusses the mechanism for reducing the concentration of explosive gas through chemical reactions.

Section 2, "On the mechanism of explosive ignition in earthquakes" discusses the possible values of UEL.

Section 3, the 2nd necessary condition for the onset of an earthquake is justified and the "pressure lock" is described.

Section 4 explains the observed earthquakes with an open "pressure lock".

Section 5, "Chemical channels in earthquakes," describes the kinetic reactions used.

Section 6, the earthquakes in Dushanbe and Tiberias are analyzed in terms of the number of earthquakes transmitted through the chemical channel.

Section 7, we consider the conditions that allow us to understand when the chemical and physical channels in earthquakes can work.

Section 8, "Decrease in the magnitude of the impending catastrophic earthquake", estimates the effects of pressure buildup using CV-40 vibrators. Examples of various phenomena that contribute to the reduction of seismicity are described, as well as the successful use of vibrators and explosions; proposals are offered in "Our proposals".

Sections 9, 10 present Conclusions and Acknowledgments.

\section{On the Mechanism of Explosive Ignition in the Foci of Earthquakes}

Natural gas consists mainly of methane $\left(\mathrm{CH}_{4}\right)$-from $70 \%$ to $98 \%$. The composi- 
tion of natural gas may include heavier hydrocarbons-methane homologues: $\mathrm{C}_{2} \mathrm{H}_{6}, \mathrm{C}_{3} \mathrm{H}_{8}$ и $\mathrm{C}_{4} \mathrm{H}_{10}$. Natural gas also contains other substances that are not hydrocarbons: $\mathrm{H}_{2}, \mathrm{H}_{2} \mathrm{~S}, \mathrm{~N}_{2}, \mathrm{Hg}$, He, and other gases. Therefore, we assume that the main possible explosives associated with earthquakes in the Tiberias are alkanes (methane, etc.), and oxygen is the oxidizing agent. Consider the following chemical reactions, which are supposed to be the main sources of ignition in the centers of the earthquake:

- A series of branched chemical chain reactions leading to explosions and the onset of an earthquake,

- Various exothermic reactions leading to thermal explosions and the onset of an earthquake.

1) Let us consider in Figure 2 (this figure from [9] p. 54) the three ignition limits of a combustible gas. The ignition limits 1 and 2 are associated with branched chemical chain reactions leading to explosions between these ignition limits 1 and 2, which occur at very low pressures. Therefore, we can conclude that chemical chain reactions are not the explosions that lead to the onset of an earthquake.

2) The ignition limit 3 in Figure 2 is related to the lower ignition limit. As the pressure increases between the ignition limits 2 and 3, the chemical reaction rate passes through a minimum and begins to increase again. At a certain pressure of the mixture, the reaction rate may turn out to be so high that the generated heat does not have time to release from the gas mixture and the temperature of the mixture begins to increase. An increase in temperature entails an even greater increase in the reaction rate. The result of this self-acceleration of the reaction is a thermal explosion. The origin of the third gas ignition limit is shown in Figure 2.

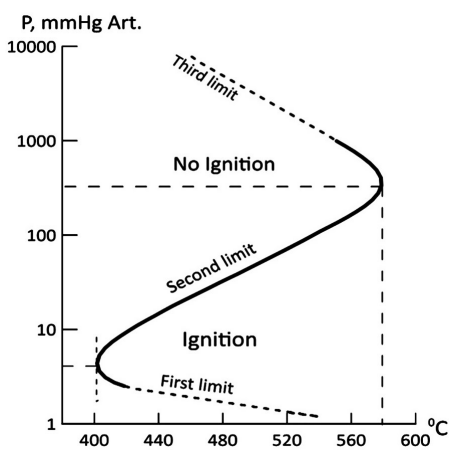

Figure 2. Ignition limits of the explosive mixture (from [9]).

Table 1. Explosive limits of various gases from the Earth.

\begin{tabular}{ccc}
\hline Gas & Lower explosion limit (LEL) volume \% & Upper explosion limit of (UEL) volume \% \\
\hline $\mathrm{CO}$ & 16.4 & 75.1 \\
$\mathrm{H}_{2}$ & 9.4 & 66.5 \\
$\mathrm{CH}_{4}$ & 4.4 & 16.4 \\
$\mathrm{H}_{2} \mathrm{~S}$ & 4.3 & 25.5 \\
\hline
\end{tabular}


The concentration of combustible gas in the air below which the combustible mixture cannot explode, but above which it can burn as a result of explosion, is called the lower explosive limit (LEL) or the third ignition limit of the gas. The gas concentration below which the explosion occurs and above which the mixture is not capable of igniting is called the upper explosive limit (UEL) or the fourth gas ignition limit.

The lower concentration limit of the methane and air mixture (3rd limit) is practically independent of pressure. Standard values of explosive limits of various gases, known in the literature, are presented in Table 1. However, its upper limit (4th limit) sharply rises with the increasing pressure of the mixture. Processing of the experimental data presented in [10] made it possible to determine the upper concentration explosive limit for methane depending on the pressure of the mixture $(P$, atm.):

$$
\mathrm{UEL}=61742-52992 \exp \left[-0.1087 P^{0.66675}\right] \%
$$

According to the author [10], the most likely sources of ignition of combustible gases in a mixture with air may be the presence of extremely explosive and unstable acetylene, salts (derivatives of acetylene)-metal acetylenides. In the proportion of acetylene presence in air from 2.2 to 81 percent by volume the mixture explodes at atmospheric pressure. The amount of heat released during the decomposition of $1 \mathrm{~kg}$ of acetylene is approximately 1.5 times greater than from the detonation of $1 \mathrm{~kg}$ of nitroglycerin, and twice as much as with the detonation of $1 \mathrm{~kg}$ of trinitrotoluene. The oxidizing agents are usually metal oxides $\mathrm{Fe}_{3} \mathrm{O}_{4}, \mathrm{MnO}_{2}, \mathrm{BaO}_{2}, \mathrm{PbO}_{2}, \mathrm{~Pb}_{3} \mathrm{O}_{4}$ or oxygen-containing salts of $\mathrm{NaNO}_{3}$, $\mathrm{Ba}\left(\mathrm{NO}_{3}\right)_{2}, \mathrm{KNO}_{3}, \mathrm{KClO}_{4}, \mathrm{KCl}_{3}$. Oxygen compounds can also serve as oxidizing agents: hexachloroethane $\mathrm{C}_{2} \mathrm{C}_{16}$, fluoroplast-3. Acetylene explodes at a temperature of about $500^{\circ} \mathrm{C}$ or pressure above $0.2 \mathrm{MPa}$. It is possible that future studies may indicate other exothermic reactions that determine the conditions of ignition of the chemical reaction in the centers of earthquakes. When the pressure passes the boundary value of the upper limit of self-ignition, the first necessary condition for an earthquake is realized [6].

\section{The 2nd Necessary Condition for the Onset of an Earthquake Is Determined by a "Pressure Lock"}

The general criterion for the onset of an earthquake should include not only the ignition conditions of the chemical reaction, but also the conditions for the subsequent propagation of the flame. In the center of earthquakes, combustible gases accumulate in the pores, which we will simulate with pipes. The normal flame propagation speed in the pipes is affected by the diameter of the pipe. It was found that the flame propagation speed decreases with decreasing pipe diameter $\mathrm{d}$. If

$$
d<d_{K R}
$$

where $d_{K R}$ is the critical diameter, the flame propagation speed becomes equal zero (Figure 3 shows the theoretical and experimental dependences of the flame propagation speed on the diameter of the pipe, from [11]). 


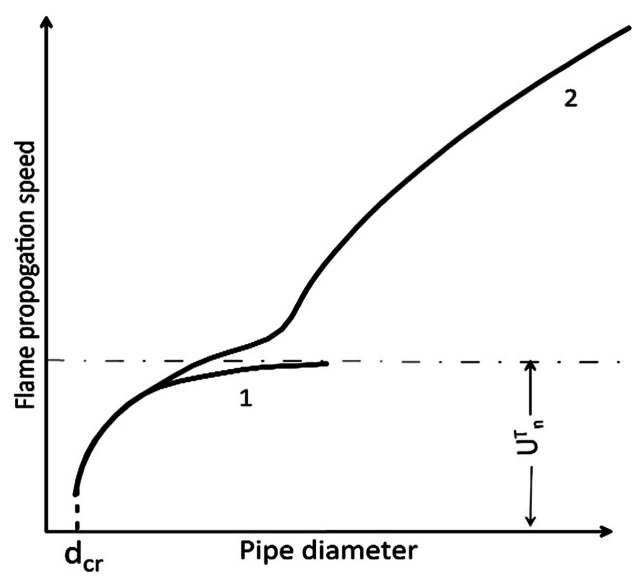

Figure 3. Dependence of flame propagation speed on the diameter of the pipe. 1-normal speed, 2-observed speed (from [11]).

The critical diameter is the maximum diameter of the pipe at which flame propagation in the combustible mixture is impossible. The explanation of this phenomenon lies in the fact that with a decrease in the diameter of the pipe, heat losses increase, in connection with this, the combustion temperature decreases, and with sufficiently large heat losses, the propagation of the flame becomes impossible. The formula for $d_{K R}$ is presented in [11] in the following form:

$$
d_{K R}=\text { const } /\left(P u_{n}\right)
$$

where $P$ is the pressure, $u_{n}$ is the normal flame propagation speed. The critical diameter is inversely proportional to pressure [11]. Formula (2) is the second necessary condition for the absence of an earthquake, depending on the pressure (even if the first necessary condition for the start of an earthquake will be fulfilled). Thus, condition (2) is a "pressure lock" that opens (with a decrease in the pressure caused by a cyclone), which leads to an earthquake or closes (with an increase in the pressure caused by an anticyclone or human interference), which can prevent an earthquake.

\section{Observed Earthquakes with Open "Pressure Lock"}

1) Observational materials [12] indicate the possibility of considering CYCLONS of atmospheric pressure as trigger effects for large earthquakes. The atmospheric pressure gradients for 42 earthquakes are shown in Table 2 and in Figure 4. Figure 4 is given in [12]. Figure 4 shows the graphs for atmospheric pressure 30 days before and 5 days after the earthquake that occurred during a cyclone. An example of atmospheric gradients pressure before an earthquake (depending on the number of days relative to an earthquake) with $M \geq 7.5$, registered on the 2 closest to the epicenter of observation points. 11/16/2003. $M=$ 7.8 Rat Islands (Aleutian Islands), Alaska.

2) Thus, the origin of thirty earthquakes in July 2018 may be associated precisely with the preceding negative gradients of atmospheric pressure in the Tiberias region [4]. 


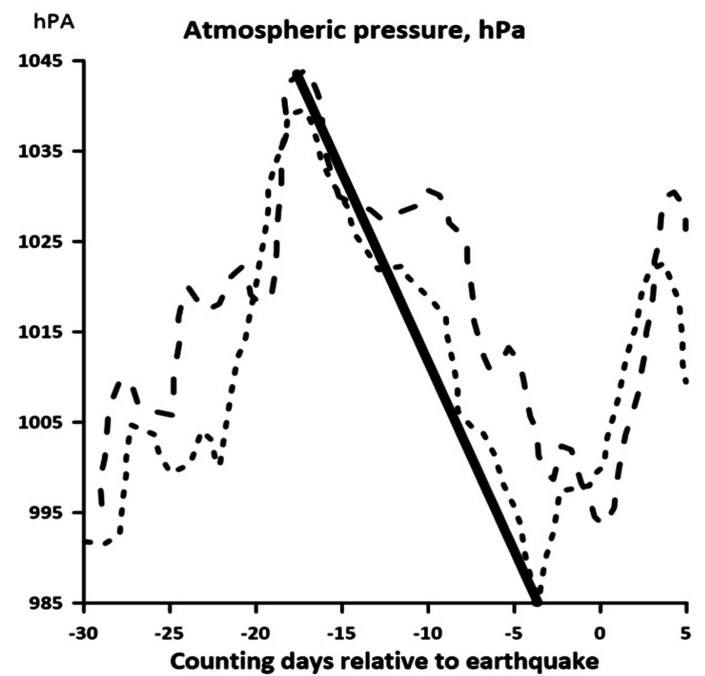

Figure 4. An example of atmospheric gradients pressure before an earthquake (depending on the number of days relative to an earthquake) with $M \geq 7.5$, registered on the 2 closest to the epicenter of observation points. 11/16/2003. $M=7.8$ Rat Islands (Aleutian Islands), Alaska. Figure 4 is given in [12]. Figure 4 shows the graphs for atmospheric pressure 30 days before and 5 days after the earthquake that occurred during a cyclone.

Table 2. Atmospheric pressure gradient distribution for earthquakes with $M \geq 7.5$.

\begin{tabular}{ccc}
\hline Gradient amplitude (mm Hg. St) & N earthquakes & 100\% Gradient amplitude/760 \\
\hline $4-10$ & 24 & $1004 / 760=0.53 \%$ \\
$10-20$ & 9 & $10010 / 760=1.3 \%$ \\
$>20$ & 9 & $10020 / 760=2.6 \%$ \\
\hline
\end{tabular}

3) Note, that the overwhelming number of earthquakes in Israel occurred precisely in the summer months, when quiet weather with warm temperatures is usually observed [13]: July 11, 1927, August 3, 1993, June 2004, June 12, 2008, July 13, 2008, July 15, 2008, April 17, 2009, April 12, 2010, March 9, 2010, March 20, 2010, July 15, 2010, August 23, 2010.

\section{Chemical Channels in Earthquakes}

In this section, the kinetics of reactions leading to ignition in the foci of earthquakes are considered. Methane is the most common explosive gas in natural gas. To describe the reaction $\mathrm{CH}_{4}+2 \mathrm{O}_{2}=2 \mathrm{H}_{2} \mathrm{O}+\mathrm{CO}_{2}$, we use the second-order kinetic reaction model [9] A0 $+\mathrm{B} 0=\mathrm{C} 0+\mathrm{D} 0$ (where A0 (methane), $\mathrm{B} 0$ (oxygen)), the kinetic reaction rate is

$$
\mathrm{d} x / \mathrm{d} t=k(a-x)(b-x)
$$

where $A(t), B(t), x(t)$ are the current concentrations, $A(0)=a, B(0)=b, x(0)=0$ where $a$ and $b$ are the initial concentrations of $A B ; x$ is the current concentrations. The solution of (4) with $x(0)=0$ is written in the form:

$$
x(t)=a b[1-\exp (k t(a-b))] /[b-a \exp (k t(a-b))]
$$




$$
A(t)=a-x(t)=a(a-b) /[a-b \exp (k t(b-a))]
$$

1) Let $b>a$.

Then $A(0)=a, A(\infty)=0$. Suppose $a>$ UEL, then an explosion will occur at some moment $T$, determined from the equation $A(T)=\mathrm{UEL}$, solving which, we will get a solution in the form

$$
\begin{gathered}
\lg T=-\lg (k(b-a))+\lg [\ln [(a / b)(1+(b-a) / \mathrm{UEL})]] \\
-\lg (k(b-a))>\lg [\ln [(a / b)(1+(b-a) / \mathrm{UEL})]]
\end{gathered}
$$

Therefore, we write an approximate formula for $\lg (T / h)$ and $T(s)$

$$
T(s) \approx 1 /[\kappa(1 / s)(b-a)], \lg (T / h) \approx-\lg (3600 k(b-a))
$$

Using Formulas (7)-(9) from [6], we write the following Formulas (10)-(11)

$$
\begin{gathered}
\mathrm{UEL}=100 N / N_{A}, E=m K_{2}=J 10^{6.5+1.449 M}, \\
m=N \mu=N_{A} \mathrm{UEL} \mu / 100=\left(J / K_{2}\right) 10^{6.5+1449 M}, \\
\mathrm{UEL}=\left(100 \mathrm{~J} / N_{A} \mu K_{2}\right) 10^{6.5+1449 M}
\end{gathered}
$$

Thus, $\log (T / h)$ weakly depends on the magnitude of $M$ and is mainly determined by the reaction rate constant $\mathrm{k}$ and the difference in initial concentrations in accordance with (9).

2) Let $a>b$.

Then $A(0)=a, A(\infty)=a-b$. Suppose $(a-b)<$ UEL. Then the explosion will occur at the moment $T$, defined by the equation $A(T)=$ UEL, solving which we get a solution in the form

$$
\begin{gathered}
\lg T=-\lg (k(a-b))+\lg [\ln [(b / a)(1-(a-b) / \mathrm{UEL})]] \\
-\lg (k(a-b))>\lg [\ln [(b / a)(1-(a-b) / \mathrm{UEL})]] .
\end{gathered}
$$

Therefore, we write an approximate formula for $\lg (T / h)$ and $T(s)$

$$
T(s) \approx 1 /[\kappa(1 / s)(a-b)], \lg (T / h) \approx-\lg (3600 k(a-b)), \text { где }\left[T_{h}\right]=[h] .
$$

Thus, $\log (T / h)$ weakly depends on the magnitude of $M$ and is mainly determined by the reaction rate constant $\mathrm{k}$ and the difference in initial concentrations in accordance with (12).

\section{Analysis of Experimental Measurements}

The results of the development of the geochemical method are described in [5] and [8]. Experimental measurements of the time of the precursor and the magnitude of earthquakes from (Figure 3(a) in [5]) are presented and interpreted below in Figure 5. In Figure 6, the same experimental measurements are presented and interpreted on the basis of the developed ideas in this article and in articles [6] [7].

1) Figure 5 presents experimental measurements of the precursor time and the magnitude of earthquakes [5]. For the first set of experiments that are inside 


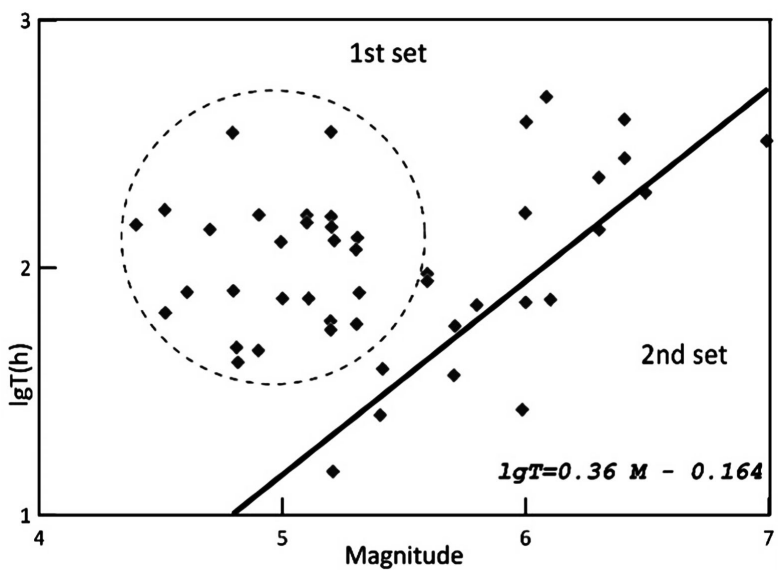

Figure 5. Experimental measurements of time precursor and the magnitude of earthquakes presented in figure 3(a) in the article [5].

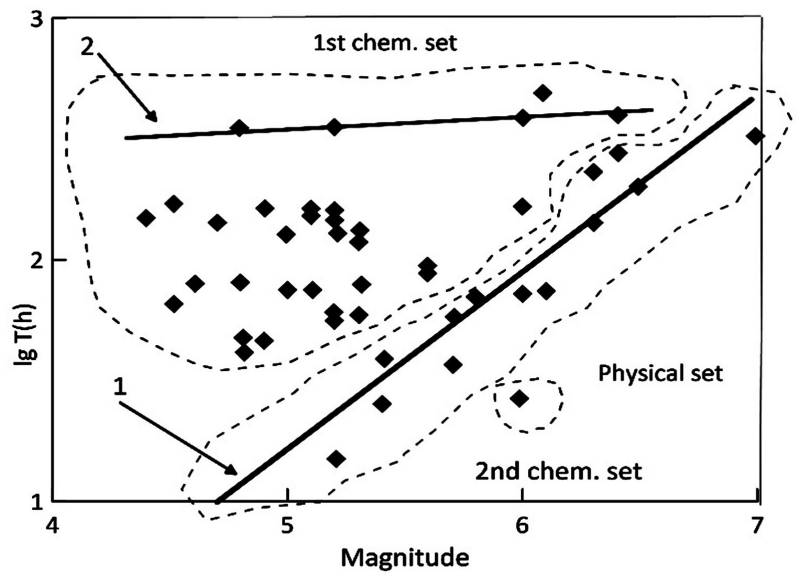

Figure 6. Classification of the experiment group of Figure 5 into groups N1 and N2 flowing through a chemical channel, and the group earthquakes that occur on the physical channel, which are located along line 1.

the dashed circle in Figure 5, the author of the experimental measurements [5] gives the following explanation "the center of location of the 1st cluster is in the value $M=5$. Perhaps, this characterizes the limit of sensitivity below which weak precursors cannot respond to an impending earthquake." The second set of experiments, to which all other experiments belong, the author of the article [5] describes by the empirical formula $\lg T=0.36 M-0.164$, which in fact can only describe earthquakes, near the straight line shown in Figure 5.

2) Based on the previously presented considerations about earthquakes in articles [6] [7] and in this article, performed via chemical and physical channels, the following classification of experiments from Figure 5 can be formulated as presented in Figure 6. Earthquakes that occur through a physical channel are located along straight line $1(\log T=a M-b)$, a formula deduced on the basis of the physical model in [6] [7], in which the coefficients $a$ and $b$ are not selectable parameters, but are deduced (this deduced formula actually coincides with the empirical formula in [5]). Let us call this group of earthquakes a "physical set". 
All other earthquakes occur through the chemical channel (groups "1-st chemical set" and "2-nd chemical set"), their number significantly exceeds the number of earthquakes that occur through the physical channel due to the scattered parameters of these earthquakes (see (9), (12)). The earthquake points that lie on the straight line N2 in Figure 6, parallel to the abscissa axis, have approximately the same reaction rate constant " $k$ " multiplied by the modulus of the difference of the initial concentration (see Formulas (9), (12)). For example, in accordance with Formula (12), direct line number 2 passes through points having approximately the same value of the reaction rate constant multiplied by the modulus of the difference in initial concentrations

$$
\begin{gathered}
\kappa(1 / s) \bmod (a-b)=7.82 \times 10^{-7}(1 / s), \\
2.55=\lg (T / h)=-\lg \left[3600 k_{2} \bmod (a-b)\right] .
\end{gathered}
$$

The set of experimental time values of the earthquake precursor in Figure 6, lying near straight line 1 , is described by a physical model and includes about $20 \%$ of all earthquakes, $80 \%$ of earthquakes can be attributed to the chemical channel for earthquakes that occurred in Dushanbe in 1983, which shows that the chemical channel is the primary one in Dushanbe.

3) It can be assumed that all the earthquakes in Tiberias in July 2018 passed through the chemical channel, which follows from the small magnitude of these earthquakes $(M<5)$.

4) Figure 7 presents the simulation $A(t)$ of experimental measurements of the time dependence of the gas flux density $\mathrm{Hg}$ presented in Figure 1 (from [5]). Thus, based on Formula (6), we can plot a graph, Figure 7, describing the implementation of the 1st necessary condition for the onset of the earthquake, shown in Figure 1. Earthquake precursor time is 73.7 hours.

\section{Chemical and Physical Channels in Earthquakes}

This section analyses the conditions that allow us to understand when the chemical and physical channels in earthquakes can work. Consider the model of the kinetic reaction of the second order [9]. The formula for $B(t)$ follows from (5) and (6)

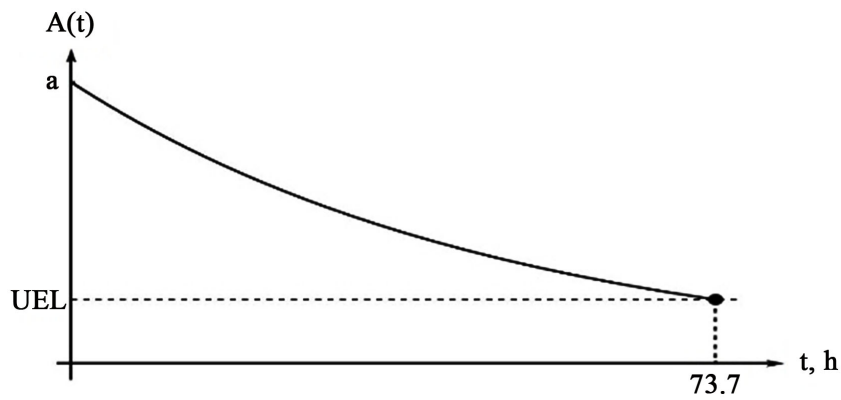

Figure 7. Modeling A ( $t$ ) of experimental measurements of the time dependence of the gas flow density $\mathrm{Hg}$ is shown in Figure 1 (this figure is presented in [5]). The precursor time is 73.7 hours. 


$$
B(t)=b-x(t)=b(b-a) /[b-a \exp (k t(a-b))]
$$

The reaction through the chemical channel is faster than through the physical channel. Therefore, the reaction proceeds through the physical channel only when the reaction through the chemical channel cannot proceed. We will analyze the course of various reactions with various initial data.

1) Let $a>b$, then $A(\infty)=a-b, B(\infty)=0$.

a) If UEL $>a-b>0$, then $A(t 2)=\mathrm{UEL}, B(t 2)=b-a+\mathrm{UEL}>0$, then $a$ chemical channel explosion occurs at time $t 2$.

b) If $A(\infty)=a-b>$ UEL, $B(\infty)=0$, then there is no explosion and the chemical channel is closed, because the methane concentration is above the threshold, and oxygen is absent. Note: the tendency of $A(t)$ to $(b-a)$ is described by exponential formulas, therefore, instead of $A(\infty)$, we take some value of $A(T 1)$. Therefore, at $t>T 1$, the chemical channel is closed, because there is no oxygen, and then the process can go along the physical channel. First, the reaction goes through the chemical channel, then the chemical channel closes and the process goes through the physical channel.

2) Let $b>a>$ UEL $x(\infty)=a$. We assume that $x(t 3)=a-\mathrm{UEL}$, then $A(t 3)=a-x(t 3)=$ UEL, which means that an explosion occurs at time $t 3$, the reaction passed through a chemical channel. Thus, the considered model made it possible to understand, what parameters are required for reactions to go through the chemical or physical channels.

\section{Decrease in the Magnitude of the Impending Catastrophic Earthquake}

1) To assess the pressure growth effect on closing the "pressure lock", and thus reduce the amplitude of a future catastrophic earthquake, the CV-40 vibrators, proposed in [7], will be used. The maximum value of the variable acoustic pressure (pressure amplitude) can be calculated using the formula

$$
P=2 \pi \dot{\rho} f c A
$$

where $P$ is the maximum acoustic pressure, $f$ is the frequency; $c$-sound propagation speed; medium density; $A$ is the amplitude of the oscillation of the particles of the medium. We use the formula for the vibrational velocity $V=2 \pi f A$ and write the amplitude in the following form

$$
P=\dot{\rho} V c
$$

where $c=7000 \mathrm{~m} / \mathrm{s}, \quad \dot{\rho}=5000 \mathrm{~kg} / \mathrm{m}^{3}$. The vibrational velocities for the $\mathrm{CV}-40$ were carried out under various frequency control systems and, as shown in Table 10 from [14], the system in which the vibrational velocity is maximum is the CV-40 sweep system $7.91-11.23 \mathrm{~Hz}$ (the measured components of the vibrational velocity at a distance of $0.6 \mathrm{~km}$ are $V x=2.6 \times 10^{5} \mathrm{~nm} / \mathrm{s}, V y=8.8 \times 10^{4}$ $\mathrm{nm} / \mathrm{s}, V Z=2.0 \times 10^{5} \mathrm{~nm} / \mathrm{s}$ ) and the total vibrational velocity is $V=3.4 \times 10^{5}$ $\mathrm{nm} / \mathrm{s}$. In terms of their energy equivalent, the parameters of the wave field generated by the powerful CV-40 vibrators in the range of $1-350 \mathrm{~km}$ are close to 
the corresponding energy parameters of the seismic field from the explosion with a TNT equivalent of $1 \mathrm{t}$. Then the pressure amplitude $P$ is $P=3.4 \times 10^{5}$ $\mathrm{nm} / \mathrm{s} \times 5000 \mathrm{~kg} / \mathrm{m} \times 37,000 \mathrm{~m} / \mathrm{s}=1.19 \times 10^{4} \mathrm{~Pa}$. The fraction $P$ of normal pressure $(P n=101,325 \mathrm{~Pa})$ is $P / P n=0.012$. Obviously, sound pressure can be increased further. For example, by increasing the frequency interval of the vibrator. The frequency should not be increased too much, because with increasing frequency, generally speaking, the absorption coefficient rises. But for low frequencies, obviously, this can be done if the task is to use a vibrator at depths up to $15 \mathrm{~km}$. The authors of [15] experimentally revealed that for dry sandstone and limestone rocks at low $(100-200 \mathrm{~Hz})$ frequencies, dissipation is practically independent of frequency. Given that the sound pressure is proportional to the frequency, for the frequency interval $79.1-112.3 \mathrm{~Hz}$, the estimated fraction $\mathrm{P}$ of normal pressure $P n$ is $P / P n=0.12$.

According to [16], experiments with the grouping of powerful vibrators have been started in order to increase the radiation amplitude. At a number of points, two vibrators can be located close to each other, at distances from 1 to $3 \mathrm{~m}$. When the vibrators reach resonance, the radiation amplitude increases by $1.2-2$ times compared to the output of single vibrators. Thus, an increase in the sound pressure reduces the critical diameter, which leads to a decrease in the magnitude of the earthquake or prevents the earthquake. The experimental data below confirm this conclusion.

2) The authors of [17] argue that a) continuous blasting in mines (and it is such in the daytime) relieves stress and leads to a decrease in the likelihood of destructive strong earthquakes; b) the regular movement of trains by rail affects the stress conditions in the neighboring territory, thereby unloading the natural seismic processes; c) the results of experiments using a powerful vibroseismic source have been presented. An assumption has been put forward about the unloading effect on the seismic activity at small distances (several hundred meters) as a result of its operation.

3) Studies of excited seismicity in the area of the dam reservoir of the Nurek hydroelectric station showed that with an increase in the level of vibrations during spillways, the average daily seismic energy, normalized to an area of 1000 $\mathrm{km}^{2}$, decreases by three orders of magnitude, and strong earthquakes disappear [18] (see Figure 8).

4) Our Proposals

a) A patent is proposed for a new device [6] [7] for recording the information about earthquake precursors using mercury measurements as an extremely strong and sensitive forerunner occurring tens of hours before an earthquake. The proposed equipment for recording information should be able to determine the epicenter of a future earthquake.

b) It is proposed to create a network of stations. At each station it is proposed to place a device for determining the epicenter of a future earthquake and a device for determining the air pressure dependence on time. If the measurements 


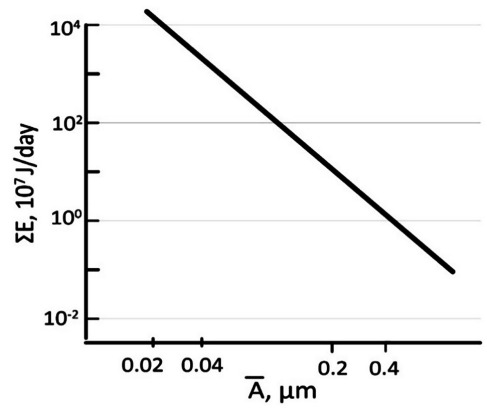

Figure 8. The graph of the average daily released earthquake energy per unit area of 1000 $\mathrm{km}^{2}$ in the water area of the Nurek hydroelectric power station depending on the level of microseisms at different distances and at different time periods for gradually receding zones within a radius of up to $25 \mathrm{~km}$ from the spillway (from [18]).

show anti-cyclone, then this pressure can lead to a decrease in the earthquake magnitude or even prevent an earthquake.

c) Having determined the epicenters of a future earthquake, in which very large flows of mercury gases are measured (and, therefore, large future earthquakes can be anticipated), it is proposed to install vibrators in the epicenters (or to make explosions), which should lower the magnitudes of future dangerous earthquakes. In addition, it is necessary to notify the population about the expected future earthquake.

d) It is proposed to launch the work on creation of specialized vibrators for the purpose of reducing the magnitude of an impending catastrophic earthquake, which will be more powerful and cheaper than the CV-40 sweep 7.91 $11.23 \mathrm{~Hz}$.

\section{Conclusions}

It was shown that the first necessary condition for the onset of an earthquake is the need for an explosive gas to enter the explosive zone for this gas through a physical or chemical reaction (in в ранее опубликованных и настоящей article). The article formulates the 2nd necessary condition for the onset of an earthquake, which consists in the fact that it is necessary to ensure the subsequent propagation of the flame after ignition. The fulfillment of the 1st necessary condition is not enough for an earthquake to occur. The 2 nd condition is the excess of the diameter of the pipe (pores in the focus) over the critical diameter inversely proportional to the pressure. This condition of the beginning of the earthquake made it possible to explain the effect of the cyclone on the beginning of 42 strongest earthquakes in the 21st century. If violation of the 2nd necessary condition for the onset of an earthquake is achieved, using vibrators or explosions, it results in a decrease in the magnitude of the earthquake or even complete prevention of earthquakes. Thus, the 2 nd condition is a "pressure lock" that opens (with a decrease in pressure caused by a cyclone), which leads to an earthquake or closes (with an increase in pressure caused by an anticyclone or human interference with the help of vibrators or explosions), which leads to 
earthquake prevention.

The second-order kinetic equations were used to describe chemical reactions and to obtain formulas for the precursor time, which made it possible to understand the difference between earthquakes of a physical channel and earthquakes of a chemical channel. The sets of parameters are found at which earthquakes by the physical channel are possible. In the future, the mathematical models used to study the physical channel should include physical and chemical processes simultaneously.

The second set of experimental values of the earthquake precursor time along the straight line 1 on Figure 6 , is described by a physical model and includes about $20 \%$ of all earthquakes; $80 \%$ of earthquakes can be attributed to the chemical channel for earthquakes that occurred in Dushanbe in 1983, which shows that the chemical channel is the primary one in Dushanbe. All earthquakes in Tiberias in June 2018 passed through the chemical channel, which follows from the small magnitude of these earthquakes.

Several proposals have been made, including: 1) to create a new sensor that allows determining the epicenter of a future earthquake; 2) to create a network of stations, with a new sensor for determining the epicenter and an atmospheric pressure meter installed at each station (this will determine if the "pressure lock" is closed by an anticyclone, which can lead to a decrease in the magnitude of earthquake or even prevent earthquake); 3) to install vibrators in epicenters (or to carry out daily explosions using trucks, drones, planes or helicopters), which should lower the magnitudes of future dangerous earthquakes; 4) it is necessary to notify the population of the expected future earthquake; 5) to launch the work on the creation of specialized vibrators for the purpose of reducing the magnitude of an impending catastrophic earthquake, which will be more powerful and cheaper than the CV-40 sweep $(7.91-11.23 \mathrm{~Hz})$.

Thus, this article is a breakthrough, describing a new mechanism in earthquakes (The Chemical Channel of Earthquake Reactions) for understanding and theory of earthquakes, which are used for the vast majority of earthquakes, including for program to reduce the magnitude of dangerous earthquakes.

\section{Acknowledgements}

The author is grateful to Lev Gilat for sending some materials and for helpful discussions. The author also thanks Valery Cherkasky for his assistance with making of figures.

\section{Conflicts of Interest}

The author declares no conflicts of interest regarding the publication of this paper.

\section{References}

[1] Bart, M.A.F.R.S. (1875) Principles of Geology, or the Modern Changes of the Earth 
and Its Inhabitants, Considered as Illustrative of Geology. Volume I, Twelfth Edition, John Murrey, London, 655 p.

[2] Reid, H.P. (1910) The California Earthquake of April 18, 1906; The Mechanics of the Earthquake. Carnegie Institute, Washington DC.

[3] Gilat, A. and Vol, A. (2005) Primordial Hydrogen-Helium Degassing, an Overlooked Major Energy Source for Internal Terrestrial Processes. HAIT Journal of Science and Engineering B, 2, 125-167. http://people.clarkson.edu/ nanosci/jse/B/vol0201B/vg040720.pdf

[4] Gilat, A. and Vol, A. (2012) Degassing of Primordial Hydrogen and Helium as the Major Energy Source for Internal Terrestrial Processes. Geoscience Frontiers, 3, 911-921. https://www.sciencedirect.com/science/article/pii/S1674987112000412 https://doi.org/10.1016/j.gsf.2012.03.009

[5] Staheev, Y.I., et al. (2000) Patent 2145098 (01.27.2000): Method of Invention for Earthquake Prediction. http://www.freepatent.ru/patents/2145098

[6] Noppe, M.G. (2019) Determining the Epicenter of a Future Short-Focus Earthquake Tens of Hours before Earthquake and Reducing the Magnitude of an Impending Catastrophic Earthquake. International Journal of Geosciences, 10, 785-799.

http://www.scirp.org/journal/ijg https://doi.org/10.4236/ijg.2019.108044

[7] Noppe, M.G. (2019) Prevention of Catastrophic Earthquakes by Means of Significantly Decreasing the Magnitude of a Future Earthquake. International Journal of Geosciences, 10, 1037-1048. https://www.scirp.org/journal/ijg https://doi.org/10.4236/ijg.2019.1012059

[8] Staheev, Y.I. (2005) Hydrogeochemical Precursors of Earthquakes. Russian Chemical Journal, 49, 110-119. http://www.chem.msu.su/rus/jvho/2005-4/110.pdf https://doi.org/10.1111/j.1365-2648.2004.03316.x

[9] Semiohin, I.A., Strakhov, B.V. and Osipov, A.I. (1995) Kinetics of Chemical Reactions. M. Publishing house of Moscow State University. 351 p. http://www.chem.msu.su/rus/teaching/semiochin/kinetika/all.pdf

[10] Kalyakin, S.A. (2009) Explosibility of Combustible Gases during Destruction of Gas-Bearing Rock Masse. Methods and Means of Creating Safe and Healthy Working Conditions in Coal Mines, 2, 34-43. http://www.blastcraft.net/files/articles/safety9.pdf

[11] Chemistry Handbook 21 Chemistry and Chemical Technology. https://www.chem21.info/page/23921524325002423300714310509919221222719309 $\underline{2167 /}$

[12] Gokhberg, M.B. and Kolosnitsyn, N.I. (2010) Trigger Mechanisms of Earthquakes. In: Adushkina, V.V. and Kocharyan, G.G., Eds., Rigger Effects in Geosystems, Academician of the Russian Academy of Sciences, Moscow, 52.

http://idg.chph.ras.ru/data_files/\%D0\%A2\%D1\%80\%D0\%B8\%D0\%B3\%D0\%B3\%D 0\%B5\%D1\%80\%D0\%BD\%D1\%8B\%D0\%B5\%20\%D1\%8D\%D1\%84\%D1\%84\%D0\% B5\%D0\%BA\%D1\%82\%D1\%8B_2010.pdf

[13] Griber, A. (2010) Earthquakes in the History of Israel.

http://alfred-griber.com/proizvedeniya/ocherki-ob-izraile/zemletryaseniya-v-istoriii zrailya

[14] Kovalevsky, V.V., et al. (2011) Experimental Evaluation of Absolute Levels of Coherent Seismic Vibrations Using Vibration Technologies. Seismic Technology, No. 3, 84-92.

https://icmmg.nsc.ru/sites/default/files/pubs/kovalevskiygezaidr._tehnologiiseysmor 
azvedki_2011.pdf

[15] Tittmann, B.R., Nadler, H., Clark, V.A. and Ahlberg, L.A. (1981) Frequency Dependence of Seismic Dissipation in Saturated Rocks. Geophysical Research Letters, 8, 36-38. https://doi.org/10.1029/GL008i001p00036

[16] Seleznev, V.S., et al. (2013) Deep Vibroseismic Research in the Far East of Russia. Problems of Informatics, No. 3, 30-41. https://readera.org/read/14320209

[17] Seleznev, V.S., Bryksin, A.A., Emanov, A.A., Emanov, A.F., Leskova, E.V. and Fateev, A.V. (2017) Trigger Effects in the Development of Induced Seismicity and the Influence of Human Being over the Natural Seismicity of Kuzbass and Baikal Regions of Russia. Proceedings of Interexpo Geo-Siberia-2017 International Scientific Conference, 4, 12-17.

http://geosib.sgugit.ru/wp-content/uploads/kongress/Sborniki/2017/\%D0\%9D\%D0 \%B5\%D0\%B4\%D1\%80\%D0\%BE\%D0\%BF\%D0\%BE\%D0\%BB\%D1\%8C\%D0\%B7\% D0\%BE\%D0\%B2\%D0\%B0\%D0\%BD\%D0\%B8\%D0\%B54.pdf

[18] Mirzoev, K.M., Nikolaev, A.V., Lucc, A.A. and Jung, S.L. (2010) Method for Removing Elastic Energy to Prevent Earthquakes. In: Adushkina, V.V. and Kocharyan, G.G., Eds., Trigger Effects in Geosystems, Academician of the Russian Academy of Sciences, Moscow, 87-96.

http://idg.chph.ras.ru/data_files/Триггерные\%20эффекты_2010.pdf 